\title{
Fatores que influenciam na melhoria incremental do processo de desenvolvimento de produtos: a experiência de uma subsidiária de uma empresa multinacional no Brasil
}

Dirk Boehe*

\author{
Cláudio Freitas $* *$ \\ Felipe Costa $* * *$
}

\section{Resumo}

0 objetivo do presente estudo de caso é mostrar que as melhorias incrementais do processo de desenvolvimento de produto podem ser entendidas em função das fortes pressões de concorrência originadas no ambiente externo da subsidiária assim como na organização interna de pesquisa e desenvolvimento (P\&D) da empresa multinacional. Do ponto de vista teórico, 0 artigo revela uma organização de $P \& D$ interna pouco comum que combina os três as formas conhecidas de estudos sobre governança: a hierarquia, o mercado e a cooperação. Nesse sentido, a empresa estudada é distinta da organização "clássica" baseada exclusivamente no controle hierárquico. Em linha com o objetivo mencionado, será mostrado que esta forma de organização é um dos principais fatores que fomentam a aprendizagem e as melhorias do processo de desenvolvimento de produtos. Este último ponto e a visão integral da organização de $P \& D$ em uma multinacional podem comunicar alguns insights instigantes para a comunidade de gestores de atividades inovadoras.

Palavras-chave: processo de desenvolvimento de produto; empresa multinacional; mercados e hierarquias

\begin{abstract}
The objective of this case study is to demonstrate that incremental improvements in product development processes can be understood as an outcome of strong competitive pressures originated both in subsidiary's external environment and in the internal organization of the multinational corporations (MNC's) R\&D activities.

From a theoretical viewpoint, the article reveals an internal $R \& D$ organization rarely found in practice which combines three elements known forms studies of organizational governance: hierarchy, market and cooperation. In this respect, the company is different from the "classical" organization which is exclusively based on hierarchical control. In line with our main objective, we will show that this combination seems to be one of the main factors that foster learning and the improvement to the product development process. The latter point as well as the comprehensive perspective of a MNC's $R \& D$ organization might also convey some useful insights from a practical point of view.
\end{abstract}

Key-words: product development process; multinacional company; markets and hierarchies

\footnotetext{
* Professor-pesquisador no curso de mestrado em administração da Universidade de Fortaleza (UNIFOR). E-mail: dirkmichaelboehe@ yahoo.com.br. Endereço: Av. Washington Soares, 1321 Bairro: Edson Queiroz - Fortaleza- CE CEP: 60.811-905

** Coordenador do laboratório de desenvolvimento de produtos da Springer Carrier. E-mail: Claudio.Freitas@ carrier.utc.com. Endereço: Rua Berto Sírio, 521 - Bairro: São Luis / Canoas-RS CEP: 92420-030

*** Gerente de engenharia da Springer Carrier Ltda. E-mail: Felipe.costa@ carrier.utc.com. Endereço: Rua Berto Sírio, 521 - Bairro: São Luis / Canoas-RS CEP: 92420030

Artigo aceito para publicação em novembro de 2004 e aceito em março de 2005.
} 


\section{Introdução}

A crescente concorrência global no mercado brasileiro no setor de refrigeração e condicionadores de ar pressiona as empresas a reduzirem seus custos e a tornarem seus produtos mais atrativos. O desafio é inovar cada vez mais, de forma mais rápida, mais econômica e ao mesmo tempo garantir uma maior qualidade final de seus produtos. Esse desafio somente pode ser vencido por um processo de desenvolvimento de produtos (PDP) eficiente. Nesse sentido, a Springer Carrier tem sido bem-sucedida, o que se reflete na crescente importância da sua filial brasileira nas atividades globais de desenvolvimento de produtos, bem como na sua sólida posição no mercado interno, num ambiente de forte concorrência.

A análise desse caso visa dar subsídios para a compreensão dos fatores que pressionam um centro de desenvolvimento de produtos a melhorar seu desempenho. Para tanto, tais fatores serão colocados em foco, tanto no âmbito da organização interna de pesquisa e desenvolvimento (P\&D) da empresa multinacional quanto do ambiente externo da sua subsidiária. Dessa perspectiva, será sustentado o argumento de que a forte concorrência, seja na organização interna da empresa multinacional como no ambiente externo da subsidiária, gera contínua pressão por melhorias do processo de desenvolvimento de produtos em termos de qualidade, custo e time-to-market. Em outras palavras, são duas fontes de pressão pela concorrência que se complementam, pois uma subsidiária que se destaca no seu ambiente externo pode estar bem posicionada para sobressair na organização interna da multinacional e vice-versa.

Para este estudo foram aproveitadas informações livremente disponíveis em jornais, na internet ou em artigos acadêmicos, bem como dados obtidos por meio de documentos internos da empresa e de entrevistas realizadas entre 2001 e 2004. Quanto às entrevistas, foram seis encontros com o antigo e o atual gerente geral e também com os dois gerentes de projetos do centro de desenvolvimento de produtos no Brasil. Feitas pessoalmente, essas entrevistas foram complementadas por outras entrevistas; dessa vez, concedidas por telefone. Para reforçar a confiabilidade das informações, diferentes versões deste estudo de caso foram revisadas e aprovadas por dois dos entrevistados. Ademais, vale mencionar que o centro também participou de uma pesquisa survey, na qual foram usados questionários estruturados. A comparação das respostas do questionário estruturado com o conteúdo deste estudo revelou coerência entre as informações.

O acompanhamento e o fato de estar próximo da empresa têm facilitado a observação de mudanças quanto à ênfase do processo e às fontes que garantem vantagens competitivas. Inicialmente, o aprimoramento contínuo do processo de desenvolvimento de produtos estava assentado numa boa infra-estrutura interna de laboratórios. Contudo, depois de alguns cortes orçamentários em 2001, o custo e a flexibilidade do processo tornaram-se elementos importantes para o desempenho da empresa estudada no seu esforço por maior qualidade de seus produtos.

\section{Concorrência e inovação}

As empresas podem influenciar suas chances de competir no mercado investindo em inovação tecnológica e aprendizagem. Da perspectiva da teoria evolucionária da mudança econômica, as firmas expostas à concorrência acionam as chamadas rotinas de busca, ou seja, processos de aprendizagem que podem levar a melhorias incrementais (NELSON e WINTER, 1982). Segundo essa lógica, a organização que implementa melhorias relevantes de forma mais rápida aumenta suas chances de sobrevivência no mercado.

Em sintonia com essa base teórica, as diferentes correntes da literatura sobre sistemas de inovação têm atribuído crescente importância à concorrência como um elemento catalisador que promove as inovações. Ao discorrer sobre as capacidades tecnológicas dos países, Lall (1992, p.171) também destaca o papel da concorrência, afirmando que é "o incentivo mais básico que influencia o desenvolvimento de capacidades" (tecnológicas). Por exemplo, para Porter (1990), a rivalidade entre as organizações, assim como a importância das exigências dos clientes, é um dos principais fatores que contribuem para a geração de dinâmicas inovadoras em uma aglomeração de empresas. 
Em um recente estudo empírico sobre a economia de aprendizagem, Lundvall e Nielsen (1999) confirmam que o desenvolvimento incremental de novos produtos é mais freqüente nas empresas que estão expostas a uma concorrência mais forte. Além disso, essas empresas também realizam mudanças organizacionais internas e externas com maior frequiência, adotando formas de organização mais flexíveis. Ainda segundo esses autores, as principais forças que geram essas pressões são as próprias mudanças tecnológicas, a possibilidade de que novos concorrentes entrem no mercado, fatores macroeconômicos que dificultam a sobrevivência das empresas - como taxas de câmbio supervalorizadas ou a abertura de mercados -e, finalmente, os regimes de governança das empresas. Em síntese, a concorrência é considerada como fundamental para a aprendizagem nas empresas, principalmente, para gerar melhorias e inovações incrementais.

Ora, ainda que a pressões da concorrência não atinjam diretamente as atividades inovadoras desenvolvidas internamente pela empresa, seus efeitos podem ser sentidos dentro dela, mais especificamente, em suas diversas unidades, como as divisões ou as subsidiárias, as quais podem competir por recursos. Nesse sentido, Hennart (1993) argumenta - a partir da teoria dos custos de transação - que elementos de ordem hierárquica e mercadológica podem coexistir numa empresa. Por esse raciocínio, o mecanismo de preços seria uma incentivo que possibilitaria a cada unidade da empresa maximizar não apenas seu desempenho, mas também o mecanismo de controle hierárquico, permitindo a cada uma dessas unidades atuar conforme as diretrizes da matriz. No entanto, ambos os elementos implicam diferentes tipos de custo, sendo o ônus da hierarquia a possibilidade de que as unidades minimizem seus esforços (shirking costs); e em relação ao mercado, a possibilidade de que as unidades inflacionem os preços ou baixem a qualidade para aumentar as margens de lucro (cheating costs). Logo, os custos da organização estão condicionados a um adequado equilíbrio entre os elementos de mercado e a hierarquia.

Em algumas empresas multinacionais foram reveladas características semelhantes a mercados internos, ou seja, formas de organização interna que usam o mecanismo de mercado e incentivam a concorrência entre as unidades da empresa. De acordo com Birkinshaw e Fey (2000), que analisaram esse fenômeno na área de pesquisa e desenvolvimento de empresas multinacionais, algumas das características dessas organizações são:

- a possibilidade do deslocamento de projetos de desenvolvimento de produtos de uma unidade para outra, dependendo do desempenho;

- a concorrência entre as unidades da empresa por projetos e os recursos necessários para desenvolvê-los (orçamento, número de funcionários e equipamentos, dentre outros);

- a hierarquia, presente no controle e na avaliação da matriz quanto ao desempenho de cada unidade, geralmente, em relação ao custo, à qualidade e ao time-to-market;

- o sistema de mercado, verificado pela livre contratação entre as subsidiárias, pois algumas delas atuam como clientes que encomendam serviços tecnológicos ou projetos completos de desenvolvimento de produto de outras subsidiárias, os fornecedores;

- a valorização do empreendedorismo, especificamente, a propensão de correr riscos, aceitando projetos difíceis e sob pressão de tempo, assim, como as iniciativas para "vender" conhecimento e habilidades para outras unidades da empresa.

Considerando a concorrência externa e a interna, em perspectiva e seguindo o raciocínio de Lundvall e Nielsen (1999), é provável que elas se complementem no sentido de contribuírem para o aprimoramento do desempenho de uma unidade de desenvolvimento de produtos. Isto, porque as unidades podem assimilar as habilidades e o conhecimento indispensáveis para a sobrevivência no ambiente externo e aplicá-los na organização interna e vice-versa, uma vez que as exigências dos dois ambientes são idênticas.

Para ilustrar esse ponto, na próxima seção, será caracterizada a forma como o centro de desenvolvimento de produtos (ou centro de projetos) de uma multinacional se insere no seu ambiente externo. Posteriormente, será abordado como a subsidiária está inserida na organização interna de pesquisa e desenvolvimento da 
multinacional Carrier Corporation. Com base nessa dupla visão, seguirão as considerações sobre o processo de desenvolvimento de produtos.

\section{A Springer Carrier em seu ambiente externo}

A Springer Carrier é uma empresa de grande porte que tem como atividade fim a produção de condicionadores de ar. A empresa nasceu de uma joint venture entre a Springer Refrigeração S.A., sediada em Canoas (RS), e a Carrier Corporation, em 1983. A Springer Refrigeração S.A. foi fundada em 1934 e começou a fabricar equipamentos de refrigeração em 1941, lançando o primeiro condicionador de ar de janela da América Latina em 1958.

A Carrier Corporation pertence a um conglomerado norte-americano, a United Technologies Corporation (UTC), uma multinacional que controla também as empresas Pratt \& Whitney (que fabrica turbinas para aeronaves), Sikorski (helicópteros), Otis (elevadores e escadas rolantes), Hamilton Sundstrand (componentes para aeronaves), United Technologies Automotive (fornecedor da indústria automobilística) e United Technologies Fuel Cells (tecnologia para geração de energia).

Depois de desenvolver o primeiro sistema de condicionadores de ar em 1902 e obter a primeira patente em 1916, a empresa Carrier Engeneering Company foi criada em 1915, começando a produzir em escala a partir de 1922. A Carrier Corporation, com sede em Farmington (EUA), faturou US $\$ 8,8$ bilhões em 2002, quando empregava cerca de 42.000 funcionários. Atualmente, está presente em 182 países.

A planta industrial da Springer Carrier continua localizada no Rio Grande do Sul. Em consequiência da abertura de mercado, a partir de 1991, a empresa começou a receber um volumoso investimento tecnológico e administrativo da Carrier Corporation. O Grupo Carrier tem fortes razões para investir na fábrica e no centro de projetos no Brasil. A principal razão seria o fato de o mercado consumidor brasileiro absorver grande parte da produção da fábrica por suas condições climáticas. Além disso, o mercado brasileiro dispõe de profissionais de grande qualificação técnica a um custo relativamente baixo. Assim, opera-se com qualidade e eficiência aliados a condições economicamente favoráveis.

Os principais produtos do portfólio são os condicionadores de ar de janela e os aparelhos split. Os aparelhos de janela, do tipo residencial, são usados para espaços menores; já os aparelhos split são usados para refrigerar grandes ambientes e produzem menos ruídos por terem o condensador externo ao ambiente. Além desses tipos, existem outros produtos para uso industrial.

Nesses segmentos, a Springer Carrier possui elevadas participações no mercado de condicionadores de ar no Brasil. Para o segmento dos aparelhos split, por exemplo, a participação chega a 60\%, equivalente a cerca de 80 mil unidades (2002). Estima-se que em 2004, o faturamento da Springer Carrier no Brasil tenha chegado a $\mathrm{R} \$ 730$ milhões.

Um de seus principais diferenciais de mercado é o fato de ser a única empresa que oferece desde equipamentos do tipo janela até sistemas centrais de refrigeração, com grande capacidade. Os equipamentos maiores são capazes de refrigerar ambientes como shopping centers, hotéis e hospitais, além de serem largamente utilizados em processos industriais.

No entanto, a concorrência nesse mercado parece ser cada vez mais acirrada. Além dos fabricantes estabelecidos como a Springer Carrier, Whirlpool/Multibrás (com suas marcas Cônsul e Brastemp), Hitachi, York e Eletrolux, entraram novos fabricantes no mercado brasileiro, como a LG (da Coréia), a Artel e a DeLonghi (Itália), as japonesas Panasonic e Sanyo e a britânica Ansett Technologia.

Além da própria dinâmica do mercado, a pressão governamental para reduzir o consumo de energia de aparelhos eletroeletrônicos parece ter acirrado a concorrência entre os fabricantes. Como os produtos são classificados pelo Inmetro - devendo ser marcados com uma etiqueta que indique o nível de eficiência 
energética - o mercado se tornou mais transparente para o consumidor. Nesse contexto, a Springer Carrier vem implementando políticas que privilegiam a excelência na qualidade da gestão e no desenvolvimento de produtos, tendo preocupação com questões ambientais.

A preocupação com a qualidade também visa projetar a empresa no cenário local e mundial, através da conquista de prêmios internacionais relacionados à qualidade. A empresa participa de alguns programas relacionados a esse assunto, como o Programa Gaúcho de Qualidade e Produtividade (PGQP), e também implementa políticas que possam aprimorar a qualidade da produção.

Como a Springer Carrier tem conseguido alavancar sua posição competitiva local dentro da empresa multinacional, será o foco da próxima seção. Para tanto, será apresentada uma visão integral da organização de pesquisa e desenvolvimento da empresa multinacional, antes de caracterizar a inserção da Springer Carrier na área de desenvolvimento de produtos dessa organização.

\section{Pesquisa e desenvolvimento na Springer Carrier}

As organizações globais de $\mathrm{P} \& \mathrm{D}$ podem ser classificadas conforme a localização das atividades de pesquisa e de desenvolvimento, respectivamente. A Carrier - que concentra suas pesquisas no país de origem, no United Technologies Research Centre (UTRC), e o desenvolvimento nos centros de projetos em diversos países anfitriões - pode ser identificada como uma organização de P\&D puxada pelo mercado (ver quadrante esquerdo superior na figura 1).

De acordo com Zedtwitz e Gassmann (2002), as atividades de pesquisa tendem a ser concentradas no país de origem, por economia de escala. Além disso, essa forma de organização permite maior eficiência organizacional, em função da coordenação central de pesquisa e desenvolvimento. Evita também a duplicação das atividades dos centros de projetos, como, por exemplo, que sejam desenvolvidos simultaneamente tecnologias ou produtos idênticos em centros diferentes.

Uma visão crítica do modelo poderia apontar para uma centralização das atividades mais inovadoras, pois os centros de projetos podem, em tese, também contribuir para a geração de novos conhecimentos. Nesse arranjo, a iniciativa de desenvolver novos produtos ou tecnologias, a alocação do orçamento, assim como as parcerias em conjunto com universidades ou centros de pesquisa no país anfitrião, precisam de autorização da matriz. O controle estrito por esta ou pelo laboratório central da corporação pode aumentar também os custos de coordenação e reduzir a flexibilidade da organização global. 
Figura 1

Estruturas organizacionais de atividades de pesquisa $(P)$ e de desenvolvimento $(D)$

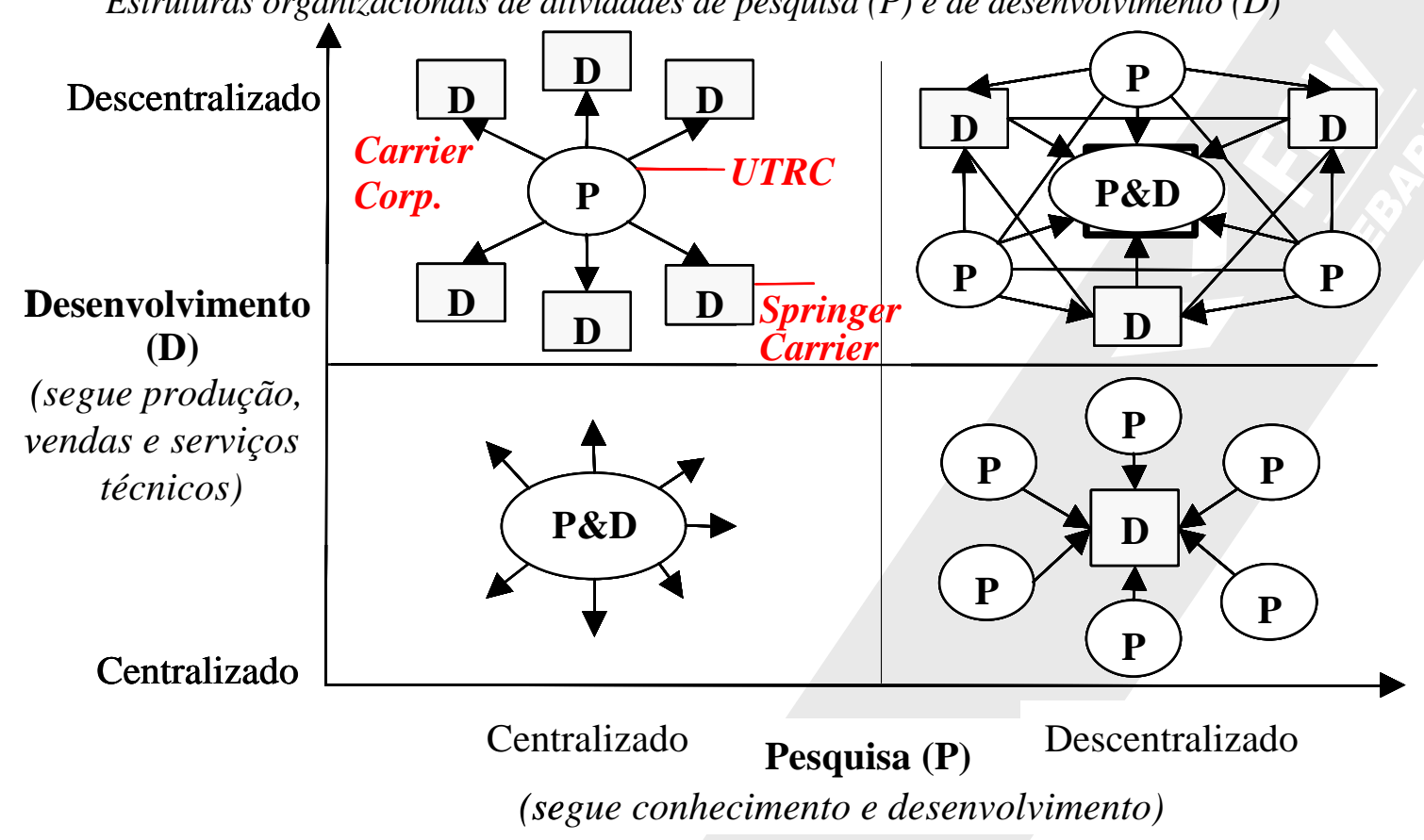

Fonte: Zedtwitz e Gassmann (2002, p.575).

\subsection{Pesquisa centralizada}

Quase todas as atividades de pesquisa básica e aplicada estão centralizadas no laboratório da empresa-mãe, no United Technologies Research Center (UTRC) em East Hartford, Connecticut, EUA. O laboratório foi criado em 1929 e emprega 450 pessoas, incluindo $160 \mathrm{PhDs}$ de um total de 250 pesquisadores. Como invoca o slogan do centro de pesquisa, Innovation. It means more than changing markets. It means creating new ones, a idéia é criar novos mercados por meio da pesquisa, technology push.

O UTRC é formado pelo Departamento de Sistemas (Systems Department) e pelo Departamento de Componentes (Components Department) que mantêm uma estreita interação. Os pesquisadores do primeiro buscam entender o funcionamento de sistemas e subsistemas de tecnologias e geram, a partir dessa abordagem, as especificações que cada componente do sistema deve cumprir. Com base nessas especificações, a equipe do segundo departamento procura realizar inovações específicas em componentes.

O volume investido em P\&D na Carrier Corporation sofreu uma retração após o ano 2000. O motivo dessa retração foi, além da crise econômica que se manifestou depois do 11 de setembro de 2001, uma mudança da estratégia, em que se passou a gerenciar o investimento em pesquisa e desenvolvimento de maneira mais organizada, dando prioridade às plataformas globais e não mais aos desenvolvimentos locais, que muitas vezes apresentavam duplicidade e falta de consistência. Dessa forma o volume investido na área de desenvolvimento de produtos da corporação voltou a apresentar um aumento gradativo para os anos subseqüentes. Os montantes foram de US $\$ 150$ milhões (2002), US\$150 milhões (2003), US\$183 milhões (2004) e uma previsão de US\$202 milhões em 2005. Cabe salientar que desses valores, $80 \%$ representam investimentos em pesquisa e desenvolvimento e o restante representa despesas (salários, infra-estrutura etc.) das áreas de desenvolvimento da corporação.

\subsection{Desenvolvimento descentralizado}

As atividades de engenharia de produtos se dividem em suporte a produtos já existentes e o desenvolvimento de novos produtos. Hoje, o grupo tem 21 centros de projetos, os chamados lead design centres. Os principais deles 
ficam nos EUA, (em sua grande maioria, responsáveis pelo desenvolvimento de plataformas de produtos tipo package), na França (respondendo pelos chilled water systems), Itália e Coréia, (responsáveis por splits) e no Brasil, o único lead design centre na América Latina, responsável por condicionadores de ar de janela. Os demais centros de engenharia, como os do México ou das Filipinas, realizam adaptações dessas tecnologias às exigências locais. Esses 21 centros de projeto não ficam necessariamente ao lado das fábricas - a Carrier possui atualmente em todo o mundo, 81 fábricas.

Além desses centros, o da China vem apresentando forte crescimento e potencial, pois o Grupo Carrier tem realizado expressivos investimentos para reforçar a capacidade tecnológica daquela subsidiária. Quanto à mãode-obra, a China pode levar vantagem em relação ao centro brasileiro, devido à disponibilidade de mão-de-obra técnica (como PhDs) que se qualifica nos EUA, e dessa forma se familiariza com a cultura americana. Pode-se deduzir das colocações de um entrevistado que o potencial para realizar pesquisa aplicada parece maior, pelo fato do centro chinês ter mais integração empresa/universidade e equipamentos de última geração. No entanto, a projeção é de que a China ainda demore algum tempo para atingir uma maturidade semelhante à do Brasil na área de desenvolvimento de produto.

A Carrier aposta cada vez mais no desenvolvimento de plataformas tecnológicas para suas famílias de produtos, sendo que cada um dos centros de projetos se especializa em uma ou mais plataformas globais. A idéia de plataforma tecnológica envolve não apenas a inovação em forma pontual, mas a criação de um clima que sempre favoreça a inovação, em que se compartilhe e reaproveite conhecimentos através de alianças ou parcerias. Sendo assim, as diversas fábricas e centros de projetos cooperam entre si no intuito de aproveitar as melhores práticas e processos desenvolvidos no grupo.

Um novo projeto global exige uma intensa troca de informações técnicas com as outras unidades. Dessa forma, a líder do projeto obtém as especificações técnicas que a nova plataforma deve cumprir, assim como dicas para melhorar o processo de desenvolvimento de produtos. Além disso, esse novo projeto global também envolve o desenvolvimento conjunto de componentes com os fornecedores. Essas relações exigem viagens para o exterior ou conferências virtuais pela internet.

Projetos conjuntos entre os diversos laboratórios, no entanto, são ainda pouco freqüentes. De um lado, não se trata de uma rede de laboratórios; por outro, existem diversos requerimentos e competências técnicas em diferentes centros de projetos pelos quais o desenvolvimento conjunto, envolvendo outros laboratórios, poderia fazer sentido. Um pré-requisito para isso seria a equalização dos laboratórios para conseguir dados válidos e confiáveis (ou seja, os mesmos dados, na mesma medida, em diferentes lugares). Contudo, há concorrência entre os centros de projeto em diferentes países pela atribuição de projetos de desenvolvimento de plataformas e produtos. Freqüentemente, os projetos são atribuídos ao centro de projetos com a melhor oferta em termos de qualidade, custos e time-to-market. Em função das diferenças de desempenho, é possível que projetos sejam deslocados entre os centros que possuem uma infra-estrutura comparável. Além disso, os centros de projetos podem vender serviços tecnológicos para outras subsidiárias, um tipo de transação bastante realizada pelo centro de projetos brasileiro.

Tendo em vista essas características e diante das considerações teóricas de Hennart (1993), pode-se notar que a multinacional implementou uma mistura de forte controle hierárquico com incentivos semelhantes aos do mercado, o que incentiva os centros de projetos a melhorarem seu desempenho.

\subsection{Desenvolvimento de produto na subsidiária brasileira}

Atualmente, o centro de projetos da empresa conta com 41 funcionários, distribuídos por cinco áreas de desenvolvimento: residencial, comercial light, comercial, laboratórios e suporte de tecnologia. Desses 41 funcionários, 25 têm graduação em engenharia com especializações e pós-graduação em áreas afins ao departamento de desenvolvimento. Os demais têm nível técnico ou estão em processo de formação acadêmica.

Durante os anos 1990, a Springer Carrier assumiu três projetos de alta complexidade, o que lhe ajudou a demonstrar sua capacidade tecnológicas à matriz. Em 1999, conquistou a responsabilidade global sobre o 
desenvolvimento de plataformas de condicionadores de ar de janela, em função da notável infra-estrutura interna, da capacitação tecnológica, do aprendizado dos engenheiros do centro e das características do mercado brasileiro. Em consequiência da crise econômica de 2001/02, a matriz determinou um corte do orçamento global; por conseguinte, o centro brasileiro sofreu uma diminuição considerável de seu quadro de funcionários, apesar do bom desempenho. Em decorrência disso, o baixo custo em relação aos centros de projetos na Europa, nos EUA e mesmo na Coréia passou a ter maior relevância para manter a responsabilidade global.

A partir de 2002, a Springer Carrier continuou sofrendo reduções, principalmente no que diz respeito à autonomia do centro brasileiro em relação ao Grupo Carrier. As principais decisões voltaram a ser centralizadas na matriz, o que tornou o processo de desenvolvimento de produtos mais rígido. As razões dessa medida convergem para um único fator central: exigência crescente de qualidade nos mercados mundiais.

Apesar dessas reduções, estima-se que o equipamento da unidade tenha crescido em $40 \%$, somente no período 2002/03. Segundo o gerente, a Springer Carrier só não atrai mais projetos para a sua unidade por já estar atuando no limite da capacidade, sem comprometimento da qualidade. Para assumir mais projetos, mantendo a qualidade, seria necessário investir em mais contratações e infra-estrutura, o que não está nos planos para o momento.

Desde o início de 2003, a Springer Carrier também desenvolve um projeto em uma área distinta, aparelhos split, que como já foi dito, são destinados a refrigerar ambientes maiores. Esse projeto estava sendo desenvolvido na Itália e, devido à evolução positiva desse segmento de mercado no Brasil, foi transferido para a fábrica de Canoas. Essas conquistas demonstram como responsabilidades ou papéis estratégicos de subsidiárias podem mudar em função de condições ambientais ou deliberações estratégicas das empresas multinacionais (BIRKINSHAW e HOOD, 1998).

Quanto às atividades de desenvolvimento no centro brasileiro, coexistem responsabilidades globais (desenvolvimento de plataformas) com adaptações de produtos que foram desenvolvidos em um dos outros centros de projetos da Carrier Corporation. Para isso, existe uma infra-estrutura interna considerável, cujo fundamento já foi criado quando a empresa ainda era de capital brasileiro. Após a compra pela Carrier, as instalações físicas (como laboratórios e câmaras de som) foram ampliadas de forma significativa. Estas são usadas inclusive por instituições governamentais para testes, o que destaca a importância relativa dos equipamentos para a infra-estrutura tecnológica do país.

Para complementar as atividades internas de desenvolvimento, são realizadas parcerias esporádicas com institutos de pesquisa e universidades. No caso da Universidade Federal do Rio Grande do Sul (UFRGS), ocorrem parcerias com o laboratório de corrosão, vapor e refrigeração e de materiais cerâmicos. Outras parcerias esporádicas para suprir necessidades mais específicas já foram realizadas com a Universidade Federal de Santa Catarina (UFSC) e o Instituto de Pesquisa Tecnológica (IPT).

Ainda não foram realizadas interações universidade/empresa na área de pesquisa aplicada. Contudo, há um projeto com um laboratório de engenharia da UFRGS que está sendo facilitado por um professor que já trabalhou no centro de pesquisa da Carrier nos EUA. O projeto, que visa criar um novo protocolo para a conectividade de redes de ar condicionado, começou no centro dos EUA e pode ser finalizado pela unidade brasileira. No entanto, parece que também aqui há empecilhos a essa interação com o meio acadêmico que dificultam a cooperação em projetos de pesquisa. As dificuldades decorrem de diferenças culturais e da divergência de objetivos, assim como de barreiras burocráticas. 


\section{Tecnologia e processo de desenvolvimento de produtos (PDP)}

Nesta seção serão abordadas as características do processo de desenvolvimento de produtos. Para tanto, serão descritos alguns aspectos da tecnologia, noções gerenciais e as principais etapas desse processo. Os fatores que têm pressionado o seu aprimoramento serão resumidos na seção subseqüente.

\subsection{A tecnologia}

Os condicionadores de ar podem ser concebidos como sistemas que envolvem um conjunto de componentes, alguns deles desenvolvidos na empresa; outros, comprados de fornecedores. Dentre os principais componentes, há o compressor (cujo custo oscila entre $40 \%$ e $60 \%$ do custo total), a chapa, o controle eletrônico, a serpentina evaporadora (absorção de calor), a serpentina condensadora (rejeição de calor) e o caracol (tecnologia para reduzir o ruído). As atividades de desenvolvimento de produtos se concentram no aumento da eficiência interna de cada componente e do conjunto em termos de ruído, consumo de energia, custo e qualidade. Além disso, busca-se explorar nichos de mercado; por exemplo, criando recursos no controle eletrônico, como reconhecimento de voz e controle pela internet, dentre outros.

Conforme exposto anteriormente, uma grande parte dos produtos da empresa se baseia em plataformas globais. Essa estratégia, semelhante ao exemplo da indústria automotiva, tem a finalidade de reduzir os custos de produção e desenvolvimento. Hoje, a Carrier conta com cinco plataformas globais de alta complexidade. Eram 18 plataformas e esse número foi reduzido pela necessidade de baixar custos e enxugar o processo em relação à quantidade de fornecedores (nacionais e internacionais) e à complexidade de montagem dos condicionadores de ar. A partir de uma plataforma, são lançadas variantes para aumentar a flexibilidade em relação a vendas, adaptações a demandas locais específicas e a fatores estéticos dos aparelhos. Atualmente, as plataformas são responsáveis por $40 \%$ da produção final das fábricas. Para os próximos anos, o objetivo dos gestores é elevar esse percentual para que, cada vez mais, as plataformas sejam utilizadas como base de todo o processo produtivo.

\subsection{Gestão de projetos no PDP}

No passado, a criatividade do inventor era considerada a principal força motriz por trás das inovações. Hoje, processos padronizados, eficientes e meticulosamente concebidos são predominantes nas atividades de desenvolvimento de produto. Semelhante à tendência verificada na indústria automotiva nos anos 1990 (FUJIMOTO, 2000), uma das principais preocupações é com a redução do tempo entre o desenvolvimento e o lançamento do produto no mercado (time-to-market ou lead time). Um processo de desenvolvimento de produtos otimizado é crucial para a redução de custos e de tempo, garantido maior qualidade.

O modelo usado na Springer Carrier está fundamentado no processo de desenvolvimento de produtos denominado Pace (Product and Cycle-time Excellence), que busca a excelência em tempo padrão. Esse modelo foi desenvolvido pela consultoria PRTM (Pittiglio, Rabin, Todd \& McGrath), em 1986, e tem sido aprimorado e utilizado ao longo dos anos como um modelo de referência de processo padrão para o desenvolvimento de produtos em empresas líderes de mercado. De acordo com McGrath (1996), o desenvolvimento de produtos é um processo que pode ser definido, estruturado e controlado, e não uma arte que depende apenas de criatividade, genialidade e inspiração, como alguns autores defendiam no passado. O Pace está baseado em sete elementos inter-relacionados que fornecem enfoques, técnicas e métodos para superar as deficiências de cada um destes elementos descritos a seguir:

- processo de decisão (comitê de aprovação);

- organização da equipe de projeto (equipes multifuncionais);

- estrutura da atividade de desenvolvimento (etapas no PDP);

- desenvolvimento de técnicas e ferramentas; 
- processo de estratégia de produto,

- gerenciamento da tecnologia;

- gerenciamento ao longo de todo o processo de desenvolvimento de produtos.

A arquitetura do Pace define o desenvolvimento de produtos como um processo integrado no qual os subprocessos, as estruturas organizacionais, as atividades de desenvolvimento, as técnicas e as ferramentas trabalham juntos em uma estrutura global única. Os sete elementos do Pace podem ser colocados em duas dimensões: a do gerenciamento "de" projetos e a do gerenciamento "entre" projetos. Os quatro elementos no gerenciamento de projetos - processo de revisão de fases, equipes multifuncionais, processo de desenvolvimento integrado e o desenvolvimento de técnicas e ferramentas - formam a base do Pace.

Depois de formatados os elementos de gerenciamento do processo, surgem novas questões a serem respondidas pela equipe de desenvolvimento de produtos: Como identificar melhores oportunidades de mercado para os produtos? Como integrar melhor a tecnologia ao desenvolvimento de produtos? Como balancear os recursos, estratégica e taticamente, ao longo do desenvolvimento dos projetos da linha de produtos? Os elementos de gerenciamento entre projetos (Figura 2) - denominados estratégia de produto, gerenciamento da tecnologia e gerenciamento ao longo de todo o PDP - fornecem a estrutura necessária para controlar e integrar esse processo como um todo.

Figura 2

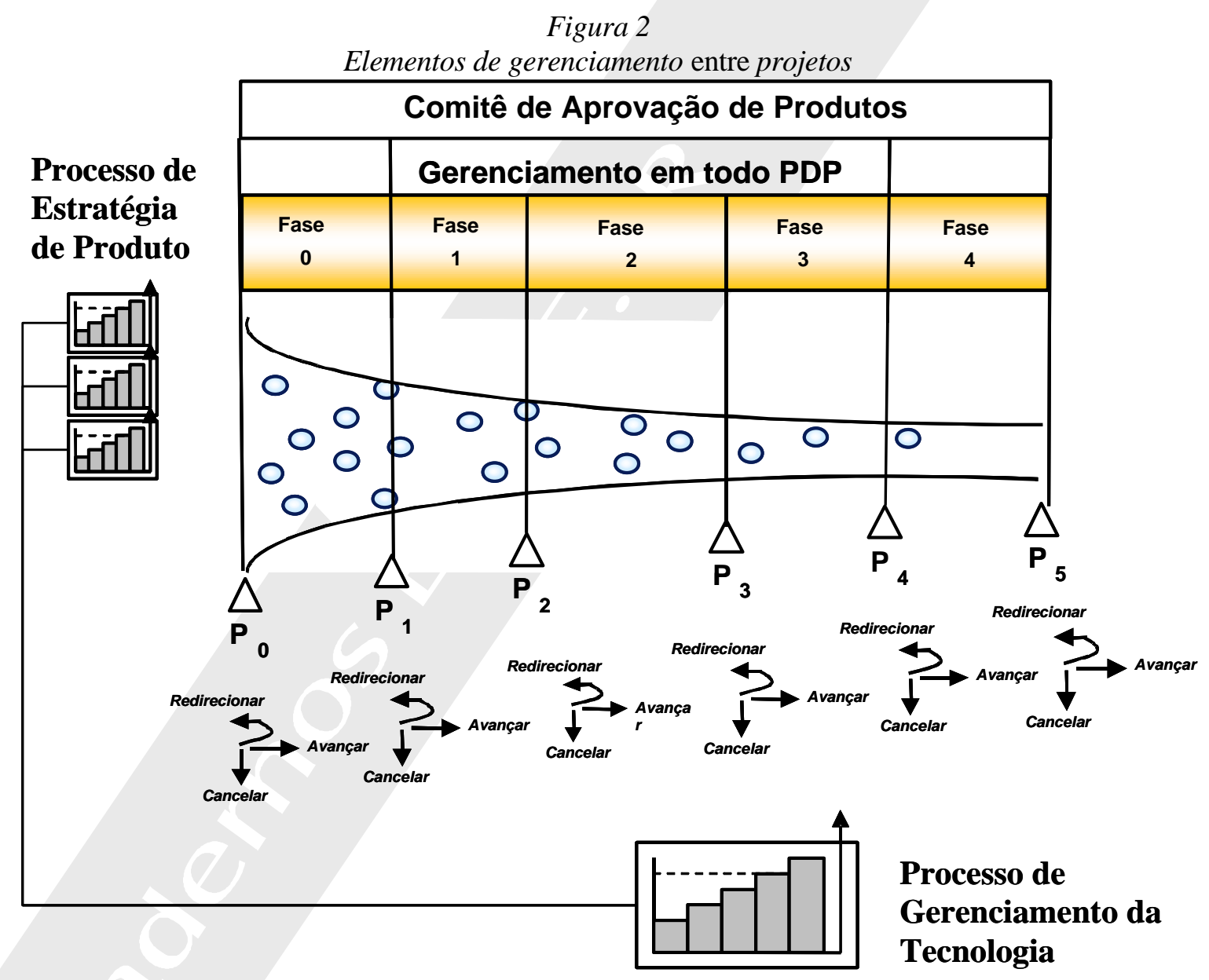

Fonte: McGrath (1996). 
Estrutura do modelo de desenvolvimento de produto e-IDS (eletronic-integrated development system). O modelo de desenvolvimento de produtos é divido em duas etapas fundamentais: a do planejamento das plataformas (o front-end do PDP) e a do sistema de desenvolvimento de produtos (o back-end do PDP).

\section{0 front- end do processo de desenvolvimento de produtos}

A maturidade e a força da estratégia de produtos de uma empresa exercem forte impacto na probabilidade de sucesso no desenvolvimento desses produtos. A qualidade dessa estratégia determina as possibilidades de desenvolvimento de novos produtos ou de adequação dos já existentes. Sem isso, as decisões podem ser forçadas, desprezando-se reais oportunidades que o mercado ofereça.

A Carrier tem um modelo genérico de desenvolvimento de produtos que é baseado na estrutura de plataformas planejadas a partir das estratégias de mercado e das tecnologias disponíveis, conforme mostra a Figura 3. A etapa inicial do processo de desenvolvimento de produtos (front-end) define uma estratégia de produtos. A estratégia definida no front-end se torna o instrumento de ligação entre a estratégia global de negócios e o processo de tomada de decisões, adotado no modelo e-IDS para validação da etapa de desenvolvimento em si (back-end), a qual será abordada mais adiante. A etapa front-end da empresa agrega itens que propiciam uma visão estratégia do produto quando da passagem por essa etapa. São estes os itens:

- foco na identificação de novas oportunidades de produtos;

- estabelecimento de uma estrutura para a estratégia de plataformas;

- direcionamento para as atividades de desenvolvimento de produtos;

- direcionamento para o desenvolvimento da tecnologia e outras funções críticas de negócios; e

- foco nas expectativas dos clientes, empregados e acionistas.

O próximo nível d front-end, a partir da criação da visão estratégica do produto, é a estratégia de plataformas de produtos. Esta orienta o processo de desenvolvimento de produtos da empresa estudada, que apresenta uma diversidade de produtos relacionados a tecnologias comuns. Por meio do conceito de plataformas de produtos, a empresa define sua estrutura de custos, capacidades e diferenciação desses produtos. Essas questões são avaliadas pela matriz em um processo de decisão que aprova, reprova ou redireciona os futuros investimentos de projetos (Figura 3), com base em elementos técnicos comuns implementados em toda a linha de produtos. Vale lembrar que esse processo de decisão está centralizado em um comitê estratégico, representado por líderes de plataformas, o que facilita o controle de metas referentes à tecnologia, vendas e orçamento, dentre outros aspectos.

A estratégia de plataformas de produtos juntamente com a visão estratégica de produtos é priorizada na Springer Carrier e antecede a estratégia de produtos, para então ser inserida no Integrated Business Plan (IBP) pela alta administração. O efeito obtido com a formulação da estratégia de plataformas reflete diretamente nos resultados de produção, estratégia de negócios de longo prazo e estratégias de tecnologias, através dos seguintes itens:

- requerimentos de marketing orientados para o vetor "diferenciação";

- expectativa do ciclo de vida das plataformas de produtos vigentes;

- limites para extensão ou não de uma plataforma;

- na avaliação sobre desenvolver ou não produtos derivados;

- orientação da necessidade de modificação da visão estratégica de produto;

- otimização da linha de produtos existentes; 
- antecipação do desenvolvimento de tecnologia avançada.

A definição e a implementação da estratégia de plataformas recebem um tratamento distinto do desenvolvimento de produtos, pois suas metas diferem nos critérios de investimento, planejamento e desenvolvimento.

\section{0 back-end do processo de desenvolvimento de produtos}

Com a definição da estratégia de plataformas, é estruturada a estratégia de produtos utilizada na etapa de backend. O e-IDS é um modelo de fases aplicado nessa etapa, para toda linha de produtos, a partir dos projetos selecionados na etapa de front-end. A seleção ocorre através das plataformas de produtos e projetos de menor porte, como requalificações de produtos existentes ou reduções de custos em linhas específicas.

As fases do e-IDS que fazem parte do back-end da empresa estudada podem ser vistas no modelo genérico de desenvolvimento de produtos na Figura 3. O passo inicial - depois de definidas as estratégias de plataformas e quais projetos são prioritários - é determinar a complexidade de cada projeto, tomando por base a ferramenta para análise de complexidade desenvolvida exclusivamente para a Carrier pela PRTM. Isso permite dimensionar o tempo padrão de desenvolvimento e os recursos necessários para cada nível do projeto.

Atualmente, os projetos são classificados pelos níveis de complexidade I, II ou III, de acordo com a análise realizada para responder as questões de complexidade relativas:

- ao mercado (geografia local ou internacional, entendimento das necessidades dos clientes e disponibilidade de dados sobre o desempenho exigido);

- aos fornecedores (necessidade de desenvolver fornecedores de alta complexidade, experiência dos fornecedores, necessidade de desenvolver canais de distribuição);

- à tecnologia de produto (porcentagem de novos componentes, modelos e ferramentas a desenvolver, duração estimada dos testes, risco tecnológico, patentes e regulamentos);

- à manufatura (número de locais de fabricação, modificações no processo de manufatura e nos equipamentos, sistemas de suporte e risco relacionados com novas tecnologias de produção) e;

- aos investimentos projetados.

Depois de definida a complexidade dos projetos começa o e-IDS, composto por cinco fases ao longo do PDP, conforme a Figura 3. A figura aponta o modelo para um projeto de alta complexidade, pois descrimina todas as fases do desenvolvimento de produtos da empresa.

Cada uma das fases deve passar por uma avaliação final, realizada pela matriz, para que, uma vez obtida a aprovação, o processo possa prosseguir. Esse procedimento é chamado de passaporte, e através dele o centro de projetos recebe do comitê estratégico de produtos as instruções para a continuidade do projeto. A avaliação da matriz pode orientar para três diferentes caminhos: para a aprovação, para o redirecionamento ou para o cancelamento. A aprovação permitirá à equipe prosseguir para a fase seguinte do projeto, quando serão disponibilizados os recursos necessários: capital humano, despesas e necessidade de testes, dentre outros.

Os casos de redirecionamento resultam de alguma insuficiência no projeto. Caso seja identificada alguma falta de informação, o comitê de aprovação ordenará que seja feita uma revisão no projeto, para que este seja completado e aperfeiçoado. Feito isso, haverá uma segunda avaliação para aprovar o passaporte.

Por fim, os casos de cancelamento podem ocorrer quando houver insuficiências mais sérias no projeto de desenvolvimento do produto. As mudanças no mercado, a inviabilidade tecnológica, a inadequação às estratégias da empresa ou um alto risco são as principais causas de cancelamentos de projetos, que também pode ser causados pela falta de verbas. 
Em função da centralização das principais decisões do processo de desenvolvimento de produtos, o centro de projetos não tem plena autonomia de decisão. Mesmo assim, é possível influenciar na aprovação dos projetos nos passaportes. Para conseguir uma aprovação, é necessário e aconselhável que a equipe conheça previamente os participantes do comitê que julgará o projeto, estabeleça um bom relacionamento profissional com os seus diretores e que haja uma relação de confiança na competência técnica; ou seja, o intercâmbio de idéias e opiniões faz com que um projeto avance muito mais completo e consistente.

\section{Figura 3.}

\section{Modelo para desenvolvimento de produto}


Fonte: interna (2002).

\section{Aprendizagem e melhoria contínua do PDP}

Uma vez consideradas as características do processo de desenvolvimento de produtos, cabe lembrar que tanto o ambiente interno quanto o ambiente externo da empresa exercem pressões para melhorá-lo. Pressões externas dizem respeito à concorrência no mercado brasileiro e internacional onde a empresa vende seus produtos. A competição no mercado brasileiro é grande devido à sucessiva entrada de novos concorrentes e a exigências governamentais que premiam produtos econômicos em termos de consumo de energia. Paralelamente às exigências governamentais que incentivam a procura de soluções técnicas superiores - exigindo mais testes e certificações durante o PDP -, a concorrência acirrada faz exige que os produtos sejam lançados no mercado cada vez mais rapidamente. É claro que isso traz implicações para o processo de desenvolvimento de produtos, que tem de ser mais ágil para que a empresa apresente eficiência e eficácia, sem abrir mão da qualidade dos seus produtos. 
O caráter diversificado e as condições, por vezes, extremas do clima no Brasil acarretam um nível de exigência ainda maior em relação aos produtos desenvolvidos no país. Além de levarem a um maior nível de exigência, tais fatores são valiosas fontes de informação, que se somam ao conhecimento trazido com as inovações apresentadas pela concorrência (HIPPEL, 1988), principalmente quando tais inovações têm origem e trajetória tecnológica diferentes. Nesse sentido, a diversidade de informações constitui um input indispensável para a aprendizagem e, dessa forma, para a melhoria contínua dos produtos e processos.

Para a melhoria do processo, a organização interna da própria empresa multinacional apresenta dois elementos principais. Em primeiro lugar, há concorrência entre os centros de projetos. O centro que oferecer melhor qualidade, custos mais baixos e menor tempo de desenvolvimento de produtos pode atrair mais projetos. Como os centros podem vender serviços para outras subsidiárias da empresa, um bom desempenho nesses indicadores é decisivo não só para custear suas atividades como para sua sobrevivência.

Em segundo lugar, está a exigência da matriz de redução de gastos e melhor qualidade do produto final. Essa melhor qualidade pode ser garantida por um processo de desenvolvimento de produtos que reduza a probabilidade de falhas no produto final. Se o centro de projetos falhar em garantir um alto nível de qualidade, perde a confiança do comitê de avaliação, podendo sofrer penalidades, como a perda de responsabilidades para plataformas e projetos de desenvolvimento de produto globais (que seriam redistribuídos entre os demais centros).

Mais adiante, um exemplo ilustra de que forma os centros de projetos aprendem, trocando informações e cooperando, ainda que em um ambiente de concorrência. Para o centro de projetos do Brasil foram atribuídos dois de 40 novos projetos estratégicos de desenvolvimento de produtos em nível global. Até o início de 2004, nenhum desses projetos tinha passado o "passaporte 4" do PDP. Quando, no final de 2003, o projeto do centro brasileiro foi redirecionado no "passaporte 3", foi necessária a contratação de consultores de uma universidade local e do exterior para procurar soluções que permitissem a aprovação na próxima tentativa. Efetuadas as melhorias necessárias, o projeto foi aprovado com louvor no passaporte vigente. A partir daí, foram sugeridas melhorias para o processo de desenvolvimento de produtos e as alterações se tornaram exemplo para outros centros de projeto. Atualmente, o exemplo bem-sucedido de Canoas é utilizado para mostrar (e oficializar) aos outros centros a importância do aprimoramento contínuo do processo de desenvolvimento de produtos. Em síntese, a base desse processo usada pelo centro brasileiro foi desenvolvida nos EUA, mas cada centro de projetos da Carrier aproveita o conhecimento de outros centros para a evolução do PDP.

Dentre as técnicas usadas para melhorar a eficiência e a qualidade do processo, foi apontada, em primeiro lugar, a terceirização de atividades relacionadas ao processo de desenvolvimento de produtos, principalmente, as análises técnicas. O potencial da terceirização é muito alto, mas esta tem que ser utilizada com cautela, pela dificuldade de se conseguir parcerias com capacitação técnica suficiente. Essa limitação pode dificultar o crescimento, pois a crescente concorrência e a corrida para o mercado praticamente obrigam as empresas a terceirizar as atividades que não estejam entre suas competências essenciais (PRAHALAD e HAMEL, 1990; NARULA, 2001).

No âmbito local, a Springer Carrier tem diversificado seus investimentos, visando qualificar seu processo. Esses investimentos vão, por exemplo, para o treinamento e a adoção de novas ferramentas (Design for 6Sigma). Por sua vez, as melhores práticas adotadas por outras empresas têm servido como exemplo para o aperfeiçoamento do processo de desenvolvimento de produtos.

Os investimentos em hardware (laboratórios e equipamentos), mencionados anteriormente, são indispensáveis para acompanhar as mudanças e para o atendimento do crescente nível de qualidade exigido. Além disso, é importante citar o uso de softwares de simulação para melhorar o processo de desenvolvimento de produtos, pois a prototipagem virtual permite soluções mais rápidas e mais exatas de eventuais problemas do que a convencional (FUJIMOTO, 2000). 
Finalmente, a cooperação com programas de pós-graduação nas universidades possibilita - pelo desenvolvimento de dissertações e teses - identificar e resolver problemas enfrentados no processo de desenvolvimento de produtos. Existe ainda uma prática denominada "prateleira de idéias", que incentiva os engenheiros a proporem melhorias que poderão ser incorporadas às plataformas e aos produtos desenvolvidos ou em desenvolvimento.

Apesar da padronização, os processos de desenvolvimento de produtos dos diferentes centros de projetos não são, e provavelmente nunca serão, totalmente iguais, haja vista que esse processo é continuamente aprimorado; logo, sabe-se "o que fazer", mas não "como fazer". Dominar o processo de desenvolvimento de produtos exige tempo para que se ganhe a experiência necessária, já que nem todos os detalhes podem ser explicitados. Somase a isso, o fato de que uma parte das técnicas permanece tácita e inseparável do contexto organizacional de cada centro de projetos. Esse aspecto torna ainda mais distante a possibilidade da matriz controlar e centralizar plenamente o processo.

Ao mesmo tempo, as conhecidas dificuldades para codificar e transferir o conhecimento tácito constituem, atualmente, uma das principais vantagens competitivas do centro brasileiro diante dos outros centros de projetos da empresa multinacional. Conforme o gerente do centro brasileiro, "a menor experiência técnica das equipes de outros centros altamente competitivos em custo, como os da Índia ou da China, lhe confere ainda um forte papel dentre os centros de projetos localizados em países emergentes".

Temos aqui um exemplo da combinação entre o conhecimento tácito acumulado e o compartilhamento de experiências com outras unidades (subsidiárias e matriz) da multinacional que alicerçam a vantagem competitiva de um centro de projetos.

\section{Considerações finais}

Este artigo mostrou a importância da concorrência como estímulo para que um centro de projetos de uma empresa multinacional inove. Mais especificamente, argumentou-se que as diferentes formas de concorrência (e outras exigências), às quais um centro de projetos de uma multinacional está exposto, podem incentivar a aprendizagem tecnológica e induzir melhorias no processo de desenvolvimento de produtos. Conforme observam Lundvall e Nielsen (1999), a pressão da concorrência conduz principalmente a inovações incrementais, mas, certamente, o caráter incremental das inovações também se deve ao fato de que a indústria de refrigeração e condicionadores de ar já atingiu um elevado grau de maturidade.

Mais do que isso, quanto à natureza das inovações, pode-se observar uma clara divisão de trabalho entre o centro de pesquisa corporativo (UTRC) e os centros de projetos nas subsidiárias. Enquanto aquele centraliza as atividades mais criativas, buscando inovações radicais, estes tentam aplicar os resultados das pesquisas do UTRC, concebendo novos produtos e plataformas por processos altamente padronizados. Se grande parte das inovações geradas pelo UTRC nascem a partir de pesquisas básicas, podendo ser caracterizadas de technology push, as inovações geradas pelos centros de projeto surgem das demandas e pressões da concorrência (technology pull).

Ainda tendo em vista o contexto teórico, verificou-se a coexistência da hierarquia e do mercado nessa organização interna de pesquisa e desenvolvimento. Visto a partir do enfoque de Hennart (1993), o que explica essa coexistência é seu potencial de reduzir os custos de organização, ou seja, a soma dos custos da hierarquia e do mercado interno. Além das implicações assinaladas por aquele autor, o uso simultâneo dos mecanismos de controle hierárquico e centralizado, a cooperação entre os centros de projeto descentralizados e os incentivos para maximizar o desempenho parecem propiciar a criação de processos de aprendizagem na organização global de pesquisa e desenvolvimento desta empresa multinacional. Talvez essa forma de organização explique, ao menos para esse tipo de indústria, algumas vantagens competitivas em comparação com outras formas de organização, tais como a centralização completa das atividades de pesquisa e desenvolvimento ou a organização em rede. 
Nesse rico campo de pesquisa, ainda podem ser explorados outros itens mais específicos, sobre os quais, contudo, a visão mais geral aqui apresentada não pôde aprofundar. O modo como ocorre no dia-a-dia essa união de elementos de controle, cooperação e de mercado, que empecilhos sofrem e suas vantagens mensuráveis são aspectos que podem ser abordados numa futura pesquisa sobre a interação entre os centros de projetos de diversos países e o centro de pesquisa corporativo, ao longo de um ou vários projetos.

Do ponto de vista gerencial, inovar passa a fazer parte de um sistema complexo que interliga elementos organizacionais e processuais que transcendem as fronteiras da própria unidade organizacional, sendo que a concepção e o gerenciamento dessas interligações se torna um desafio de primeira ordem para as empresas que buscam aumentar suas chances de sobrevivência.

\section{Referências bibliográficas}

BIRKINSHAW, J. e FEY, C. Building an Internal Market System: Insights from Five R\&D Organizations, In: The Flexible Firm: Capability management in network organizations, Birkinshaw J., Hagstrom, P. (eds.), Oxford, Oxford University Press, 2000, p. 149-175.

BIRKINSHAW, J.; HOOD, N. Multinational subsidiary evolution: capability and charter change in foreign- owned subsidiary companies. The Academy of Management Review, v.23, n.4; p.773-796, 1998.

FU IM OTO, T. Shortening lead time through early problem- solving - a new round of capability-building competition in the auto industry. In: JÜRGENS, U. New product development and production networks. Berlin: Springer, 2000.

HENNART, J.-F. The swollen middle: a mix of market and hierarchy. Organization Science, v.4, n.4, p.529-547, 1993.

VON HIPPEL, E. v. The sources of Innovation, New York, Oxford University Press, 1988.

LALL, S. Technological capabilities and industrialization. Word Development, v.20, n.2, p.165-186, 1992.

LUNDVALL, B.- $\AA$.; NIELSEN, P. Competition and transformation in the learning economy - illustrated by the Danish case. Revue d'Economie Industrielle, n.88, p.67-90, 1999.

MCGRATH, E. Setting the PACE in product development: a guide to product and cycle-Time excellence. Revised edition. Butterworth: Heinemann, 1996. 184p.

NARULA, R. Choosing between internal and non-internal R\&D activities: some technological and economic factors. Technology Analysis \& Strategic Management, v.13, n.3, p.365-387, 2001.

NELSON, R.; WINTER , S. An Evolutionary Theory of Economic Change. Cambridge (MA), Belknop Press, 1982.

PORTER, M. The competitive advantage of nations. London: McMillan, 1990.

PRAHALAD, C.; HAMEL, G. The core competence of the corporation. Harvard Business Review, v.68, issue 3, p.79-92, 1990.

ZEDTWITZ, M.; GASSMANN, O. Market versus technology drive in R\&D internationalization: four different patterns of managing research and development. Research Policy, v.31, p.569-588, 2002. 